\title{
Randomised controlled trial of biofeedback training in persistent encopresis with anismus
}

\author{
Terry Nolan, Tony Catto-Smith, Carolyn Coffey, Judy Wells
}

\begin{abstract}
Background-Paradoxical external anal sphincter contraction during attempted defecation (anismus) is thought to be an important contributor to chronic faecal retention and encopresis in children. Biofeedback training can be used to teach children to abolish this abnormal contraction.

Methods-A randomised controlled trial in medical treatment resistant and/or treatment dependent children with anismus using surface electromyographic (EMG) biofeedback training to determine whether such training produces sustained faecal continence. Up to four sessions of biofeedback training were conducted at weekly intervals for each patient. Anorectal manometry was performed before randomisation and six months later. Parents of patients completed the "child behaviour checklist" (CBCL) before randomisation and at follow up.
\end{abstract}

Results-Sixty eight children underwent anorectal manometry and EMG. Of these, 29 had anismus (ages 4-14 years) and were randomised to either EMG biofeedback training and conventional medical treatment (BFT) $(n=14)$ or to conventional medical treatment alone $(n=15)$. All but one child were able to learn relaxation of the external anal sphincter on attempted defecation. At six months' follow up, laxative free remission had been sustained in two of 14 patients in the BFT group and in two of 15 controls (95\% confidence interval (CI) on difference, $-24 \%$ to $26 \%$ ). Remission or improvement occurred in four of 14 patients in the BFT group and six of 15 controls ( $95 \%$ CI on difference, $-46 \%$ to $23 \%$ ). Of subjects available for repeat anorectal manometry and EMG at six months, six of 13 in the BFT group still demonstrated anismus $v 11$ of 13 controls (95\% CI on difference, $-75 \%$ to $-1 \%)$. Of the four patients in full remission at six months, only one (in the BFT group) did not exhibit anismus. Rectal hyposensitivity was not associated with remission or improvement in either of the groups. Mean CBCL total behaviour problem scores were not significantly different between the BFT and control groups, but there was a significant improvement in CBCL school scale scores in the BFT group, and this improvement was significantly greater than that seen in the control group.
Conclusions-The result of this study, together with those reported in other controlled trials, argues against using biofeedback training in children with encopresis.

(Arch Dis Child 1998;79:131-135)

Keywords: encopresis; anismus; biofeedback; electromyography; randomised controlled trial

Encopresis is a common and disabling disorder of childhood. ${ }^{1}$ Treatment with behaviour modification, aimed at promoting regular toileting, and the use of laxatives result in short term acquisition or resumption of continence in $50-60 \%$ of affected children, and improvement in most of the remainder. ${ }^{2}$ However, those who do not quickly acquire continence have continued difficulty with soiling and/or dependence on laxatives; this can last for many years, ${ }^{2-4}$ with a consequent negative impact on behaviour, social adaptation, and scholastic function. ${ }^{5}$

More than $50 \%$ of children who continue to soil have abnormal defecation dynamics on anorectal manometry, notably paradoxical external anal sphincter contraction during attempted defecation. ${ }^{67}$ This response is thought to promote faecal retention and subsequent overflow incontinence. Biofeedback training, which aimed to teach children how to abolish this maladaptive response, was a logical strategy to overcome prolonged retention and incontinence. Early reports, from both uncontrolled and controlled studies, produced encouraging results but, more recently, there has been conflicting evidence on whether it can promote sustained faecal continence. ${ }^{4-13}$

We conducted a randomised controlled trial in treatment resistant and/or treatment dependent children using surface electromyographic (EMG) biofeedback training in children with anismus.

\section{Methods}

A two group randomised controlled trial of EMG biofeedback training was carried out in children who had multimodal treatment resistant or laxative dependent encopresis, and who also had anismus on anorectal manometry. The principal outcomes were remission of faecal incontinence and lack of need for laxative treatment at six months' follow up. This study was approved by the Royal Children's Hospital ethics in human research committee, and randomisation took place only after full written informed consent was provided by parents or guardians of eligible subjects. 
Children were eligible for study entry if: (1) they were aged 4 years or more and were judged to be of adequate maturity to cooperate with biofeedback treatment; (2) they had received three months or more of conventional multimodal therapy; (3) they had continuing soiling with or without laxative treatment (more than once a month) or had achieved remission from soiling but could not sustain continence without continued laxative treatment; and (4) they had anismus on EMG during anorectal manometry. Subjects were ineligible if they had a known structural congenital or postoperative anatomical defect (such as spina bifida or anorectal malformation), or Hirschprung's disease (excluded by rectal biopsy only if clinically indicated).

Originally, we planned to recruit 25 subjects into each group, which would mean that, at the $\alpha=0.05$ level (one tailed), there would be $80 \%$ power to detect at least a $38 \%$ point advantage of biofeedback (32\% against $70 \%$ or better) in the comparison group. An interim analysis was conducted when it became clear that successful and sustained biofeedback outcomes were not occurring. A revised sample size calculation was based on the argument that if we were to achieve no successful outcomes in 15 subjects randomised to biofeedback, we would be $95 \%$ confident that the true rate of successful outcome could not be greater than $18 \%$. The precision of the final result was expressed in the confidence interval (CI) around the difference in remission rates.

SUBJECTS

Sixty eight children referred from an encopresis or gastroenterology clinic were eligible and underwent anorectal manometry and EMG. Of these, 29 had anismus (aged 4.8-14.9 years) and had parents who consented to randomisation. A detailed report on the manometric and clinical characteristics of all clinically eligible subjects has been published elsewhere. ${ }^{6}$ Apart from failure to demonstrate anismus, four subjects were considered ineligible on other grounds, two of whom were judged to be too immature for biofeedback training. No parent of an eligible child refused consent.

MEASURES

Anorectal manometry was performed at baseline and six months after randomisation by a gastroenterologist (TCS). The gastroenterologist was blinded to the clinical details of the patient and group assignment at the time of the second anorectal manometry. Abdominal radiographs were also carried out before anorectal manometry. These were later scored blindly for faecal retention. ${ }^{14}$ Anorectal manometry was performed at least one hour after disimpaction with two Microlax enemas (one in the evening before anorectal manometry, one in the morning) in the left lateral position (except balloon defecation into the toilet), using a pneumohydraulically perfused multilumen catheter with four sideholes at $0.5 \mathrm{~cm}$ intervals (Arndorfer hydraulic capillary infusion system; SDR Clinical Technology, New South Wales, Australia). Each lumen was con- nected to a pressure transducer and a multichannel polygraph recorder (Narco Biosystem MMS100 dynograph; SDR Clinical Technology). A terminal rubber balloon (size $2.5 \times 6 \mathrm{~cm}$ ) capable of distension to $200 \mathrm{ml}$ was attached to the probe. The distances from the furthest (distal) and the nearest sideholes to the balloon base were $5.5 \mathrm{~cm}$ and $4 \mathrm{~cm}$, respectively. Sphincter identification was by the slow station pull through technique. The catheter was withdrawn progressively in $0.5 \mathrm{~cm}$ increments until resting external anal sphincter pressure could be recorded by the distal channel. This resulted in the base of the balloon being positioned between $5.5 \mathrm{~cm}$ and $7 \mathrm{~cm}$ from the anal verge. The midpoint of the resting oscillations of the manometric recording was taken as the baseline pressure. The extreme of the deviation from this baseline was recorded as the response to stimulus.

EMG was carried out with an integrated electromyograph (Urolab model 1154; Life Tech, Houston, Texas USA) recording at $5 \mathrm{~mm} / \mathrm{second}$ with a filter of either 20,50 , or $100 \mu \mathrm{V} / \mathrm{cm}$, depending on the size of the signal. Three surface electrodes were used with two electrodes placed immediately adjacent to the anus and a reference electrode on the thigh. When recording electromyographic activity during straining, the accompanying increase in intra-abdominal pressure was monitored to ensure that the patient was pushing or squeezing correctly. Alterations in the balloon pressure were used to indicate changes in rectal (abdominal) pressure with a minimum increase of $50 \mathrm{~mm} \mathrm{Hg}$ required for correct voluntary straining and no increase for correct squeezing.

For balloon defecation, a tube with an inflatable rubber balloon attached was inserted into the rectum with the patient in the left lateral position. The balloon was inflated with $100 \mathrm{ml}$ warm water and the child then asked to defecate this into the toilet. If this did not occur within two minutes, $50 \mathrm{ml}$ water was withdrawn and the attempt was repeated. Similarly, another $20 \mathrm{ml}$ was withdrawn if defecation still did not occur (leaving $30 \mathrm{ml}$ ) and if this was still unsuccessful the equipment was removed.

Anorectal manometry measures are described in detail elsewhere ${ }^{6}$ and included the threshold for the recto-anal inhibitory reflex and transient sensation threshold, and threshold of lasting urge (30 seconds) to defecate. The procedure to determine whether anismus was present involved the use of a balloon filled with $50 \mathrm{ml}$ warm water. After a tuition period to explain what was required to achieve correct straining and squeezing, the patient was asked to make five alternating attempts each to squeeze and strain. Normal strain response was defined as a persistent decrease in external anal sphincter activity (measured by a decrease in amplitude of the electromyographic recording and an increase in rectal pressure of at least $50 \mathrm{~mm} \mathrm{Hg}$ ) in at least three of five attempts. A persistent increase in external anal sphincter activity with a corresponding increase in rectal pressure in at least four of five attempts were deemed as indicating anismus. ${ }^{75}$ 
Table 1 Baseline comparison of biofeedback and control groups

\begin{tabular}{|c|c|c|c|c|}
\hline & \multicolumn{2}{|c|}{ Biofeedback $(n=14)$} & \multicolumn{2}{|c|}{ Control $(n=15)$} \\
\hline & $n$ & $\%$ & $n$ & $\%$ \\
\hline Mean (SD) age (years) & $9.2(2.7)$ & & $8.4(2.3)$ & \\
\hline Low socioeconomic status & 6 & 43 & 3 & 20 \\
\hline Boys & 13 & 93 & 11 & 73 \\
\hline Palpable stool & 8 & 57 & 10 & 67 \\
\hline Primary encopresis & 12 & 86 & 9 & 60 \\
\hline Used laxatives & 11 & 79 & 13 & 87 \\
\hline Used oils & 8 & 57 & 11 & 73 \\
\hline Used suppositories & 2 & 14 & 1 & 7 \\
\hline Used enemas & 1 & 7 & 1 & 7 \\
\hline Used any medication & 14 & 100 & 15 & 100 \\
\hline \multicolumn{5}{|l|}{ Clinical retention } \\
\hline Mild & 4 & & 2 & \\
\hline Moderate & 8 & 57 & 11 & 73 \\
\hline Severe & 2 & 14 & 2 & 13 \\
\hline \multicolumn{5}{|c|}{ Compliance with behaviour modification } \\
\hline Moderate & 5 & 36 & 5 & 33 \\
\hline Good & 9 & 64 & 10 & 67 \\
\hline \multicolumn{5}{|l|}{ Compliance with medication } \\
\hline Poor & 0 & & 1 & \\
\hline Moderate & 3 & 21 & 1 & 7 \\
\hline Good & 11 & 79 & 13 & 87 \\
\hline Urge to stool & 14 & 100 & 13 & 87 \\
\hline Aware of soiling & 8 & 57 & 8 & 53 \\
\hline Nocturnal enuresis & 7 & 50 & 6 & 40 \\
\hline Diurnal enuresis & 2 & 14 & 1 & 7 \\
\hline Mean (SD) faecal retention score & $12.4(6.4)$ & & $14.2(6.8)$ & \\
\hline Raised transient sensation & 10 & 71 & 11 & 73 \\
\hline Raised prolonged sensation & 7 & 50 & 7 & 50 \\
\hline Incorrect squeeze & 2 & 14 & 6 & 40 \\
\hline Unable to defecate $100 \mathrm{ml}$ balloon & 7 & 50 & 9 & 60 \\
\hline Unable to defecate any balloon & 2 & 14 & 1 & 7 \\
\hline
\end{tabular}

The "child behaviour checklist" $(\mathrm{CBCL})^{16}$ was completed by parents before randomisation, and at six months. Randomisation was carried out using a stratified, blocked schedule, with subjects stratified on the basis of whether they were soiling or were in laxative dependent remission. Each treatment allocation was recorded on a card in an opaque numbered and sealed envelope and stored sequentially. An individual not connected with the clinic or the study carried out the randomisation plan.

EMG BIOFEEDBACK TRAINING

The aim of the biofeedback was to eliminate anismus during defecation attempts. No bowel preparation was required. The training procedure was conducted with the patient in the left lateral position. External anal sphincter activity was displayed using the EMG procedure described above, and abdominal pressure was displayed via a simple pressure gauge attached to a $12 \mathrm{FG}$ water filled Woodward catheter terminating in a balloon and incorporating a three way stopcock. The balloon was inserted into the rectum with its base $6 \mathrm{~cm}$ from the anal verge and was inflated with $40 \mathrm{ml}$ warm water. The gauge was calibrated to read $0-50 \mathrm{~mm} \mathrm{Hg}$ and was adjusted to zero for resting rectal pressure. Both recording devices could be seen by the patient but his attention was focused on the electromyograph recorder that indicated external sphincter contraction or relaxation both

Table 2 Treatment outcome of biofeedback and control groups

\begin{tabular}{lll}
\hline & $\begin{array}{l}\text { Biofeedback } \\
(n=14)\end{array}$ & $\begin{array}{l}\text { Control } \\
(n=15)\end{array}$ \\
\hline Full remission & $2(14 \%)$ & $2(13 \%)$ \\
Improved & $2(14 \%)$ & $4(27 \%)$ \\
No improvement & $10(71 \%)$ & $9(60 \%)$ \\
\hline
\end{tabular}

visually and aurally. Up to four sessions at weekly intervals were conducted for each patient, each session consisting of 30-35 defecation attempts. The aim was to achieve 10 relaxations of the external anal sphincter without visual feedback in two successive sessions. If this occurred in less than four sessions then biofeedback was discontinued.

At the completion of biofeedback training, subjects were followed at monthly intervals by a single paediatrician, who gave verbal reinforcement of the skills learned during training. Both groups were telephone monitored monthly by the research assistant. Medication use was decreased to a level consistent with maintenance of continence as monitored in the diary following anorectal manometry for both groups, and both biofeedback and control subjects continued standard multimodal treatment and diary monitoring, as described above and elsewhere. ${ }^{2}$

Full remission was defined as no medication and no soiling for at least four weeks; full remission on medication was defined as on medication and no soiling for at least four weeks; partial remission was defined as soiling no more than once a week, regardless of medication used. The use of medication was attempted by all those not in full remission, not only those who were worse or not improved. The remainder were those who were soiling more than once a week, regardless of medication use. Improvement was defined as progression by at least one level from baseline status, but without achieving full remission.

The presence or absence of continued soiling was ascertained on the basis of parental report, assisted by daily diary record. ${ }^{3}$ Patient data were recorded prospectively in a relational database that was also used for appointment scheduling and data quality control. The CBCL was scored using the computer program by Achenbach. ${ }^{16}$ Comparison of numbers of subjects in various outcome categories was carried out using the Fisher exact test and $\chi^{2}$ test. CBCL scores and continuous manometric results were compared with the Student's $t$ test.

\section{Results}

Table 1 gives the pre-randomisation clinical characteristics, anorectal manometry results, and CBCL scores of patients. Most patients were boys and 21 had primary encopresis. All had used some form of laxative, stool softener, or rectal medication, and all but one subject had complied well or moderately well with toileting routine and prescribed medication. At the time of randomisation, nine of 14 biofeedback subjects and 14 of 15 controls were still using oral laxatives. Of the six subjects not taking oral medication, five had ceased because it worsened their incontinence. The sixth was the non-compliant subject (biofeedback group).

Thirteen had nocturnal and three had diurnal enuresis. There were slightly more subjects with primary encopresis in the biofeedback group. Anorectal manometry revealed that 21 had an abnormally high transient rectal sensation threshold, 14 had abnormally high prolonged rectal sensation threshold, and 16 were 
Table 3 Child behaviour checklist results (standardised scores)

\begin{tabular}{|c|c|c|c|c|c|c|c|}
\hline \multirow[b]{2}{*}{ Scale } & \multicolumn{3}{|c|}{ Biofeedback group } & \multicolumn{3}{|c|}{ Control group } & \multirow[b]{2}{*}{$\begin{array}{l}p \text { value difference } \\
\text { change }\end{array}$} \\
\hline & Baseline & 6 months & $\begin{array}{l}\text { p value } \\
\text { change }\end{array}$ & Baseline & 6 months & $\begin{array}{l}\text { p value } \\
\text { change }\end{array}$ & \\
\hline Behaviour & $59.2(13.4)$ & $60.5(10.9)$ & 0.45 & $56.1(8.1)$ & $54.5(10.3)$ & 0.21 & 0.43 \\
\hline Activity & $43.5(6.4)$ & $44.7(7.1)$ & 0.60 & $44.5(6.6)$ & $44.9(6.5)$ & 0.90 & 0.94 \\
\hline Competence & $40.1(9.0)$ & $44.5(9.6)$ & 0.12 & $41.3(6.5)$ & $44.4(5.7)$ & 0.19 & 0.71 \\
\hline School & $39.4(6.6)$ & $44.7(5.9)$ & 0.002 & $47.9(4.2)$ & $49.3(3.1)$ & 0.14 & 0.04 \\
\hline Social & $42.3(11.4)$ & $45.5(6.1)$ & 0.32 & $41.5(8.4)$ & $44.3(5.2)$ & 0.26 & 0.93 \\
\hline
\end{tabular}

Values are mean (SD)

^For comparison of biofeedback group change to control group change over 6 months.

unable to defecate a $100 \mathrm{ml}$ water filled balloon within two minutes, while three were unable to defecate a balloon of any volume. The CBCL results showed that the BFT group scored higher on summary behavioural problems than controls, although much of this difference was attributable to a single high scoring outlier in the BFT group. The distribution on the competence scales was similar except for scholastic competence.

Three of the 14 patients in the BFT group completed the training in three sessions, and the remainder underwent four sessions. Only one patient was unable to demonstrate relaxation of the external anal sphincter with attempted defecation. Only one patient (the same one) was unable to defecate the biofeedback balloon by the time of their final session. All complied well with instructions and procedures involved in the training. Two complained of transient discomfort when the biofeedback apparatus was inserted. No other adverse effects were seen or reported.

Follow up assessment at six months revealed laxative free remission in two of 14 of the patients in the BFT group and two of 15 controls ( $95 \%$ CI on difference, $-24 \%$ to $26 \%$; table 2). Remission or improvement occurred in four of 14 patients in the BFT group and six of 15 controls ( $\mathrm{p}=0.7 ; 95 \%$ CI on difference, $-46 \%$ to $23 \%$ ). Of subjects available for repeat anorectal manometry and EMG at six months, six of 13 in the BFT group still demonstrated

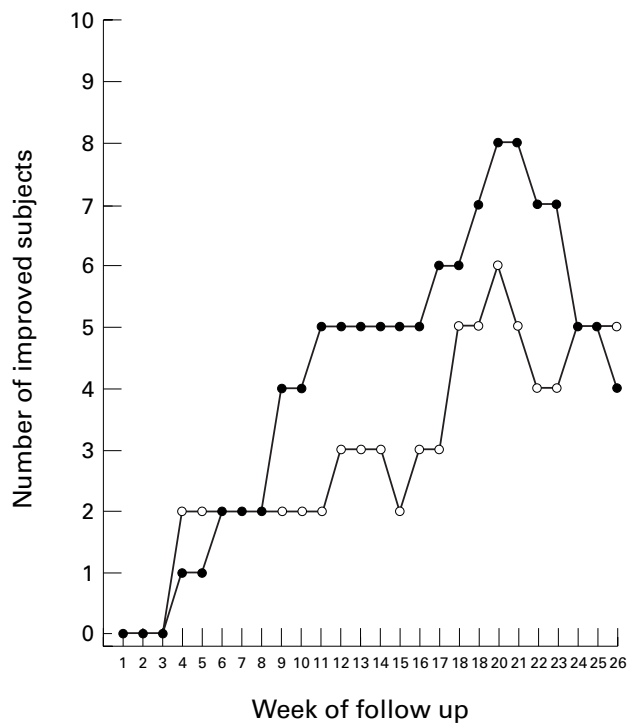

Figure 1 Number of improved subjects in biofeedback (solid circles) and control (open circles) groups over 26 weeks of follow up. anismus $v 11$ of 13 controls $(p=0.039 ; 95 \%$ CI on difference, $-75 \%$ to $-1 \%$ ). Of the four patients in full remission at six months, only one (BFT group) did not exhibit anismus.

Figure 1 shows that although there appeared to be a marginal, transient advantage for the BFT group compared with the control group between eight and 18 weeks following randomisation, there was convergence in clinical status by the end of the study period.

The extent of faecal retention at baseline, as measured by the radiograph faecal retention score, showed different patterns in BFT and control patients in relation to subsequent outcome status. In the BFT group, the mean (SD) scores at baseline were 9.0 (5.8) and 13.8 (6.4) $(p=0.17)$ in subsequently improved subjects and subjects who showed no improvement, respectively. For controls, mean (SD) values were 10.6 (4.2) and 6.7 (7.3), respectively $(p=0.21)$. Rectal hyposensitivity was not associated with remission or improvement in either of the groups.

Mean CBCL total behaviour problem scores and changes in CBCL scores over the study period were not significantly different between BFT and control groups (table 3). However, there was a significant improvement in school scale scores in the BFT group ( $p=0.002)$, and this improvement was significantly greater than that seen in the control group $(\mathrm{p}=0.04)$.

\section{Discussion}

We found no evidence of a lasting benefit in clinical outcome for biofeedback training in children who had treatment resistant or treatment dependent encopresis associated with abnormal defecation dynamics.

In addition to our study, there are three other published, small, randomised controlled trials of biofeedback training in children with encopresis. ${ }^{4121315}$ All four studies have failed to show sustained clinical improvement in continence after biofeedback training compared with controls treated conventionally. Both the study by Loening ${ }^{415}$ and our own study showed transient clinical improvement in the months or weeks following cessation of biofeedback training, with subsequent convergence with the control experience.

This disappointing clinical outcome occurred despite achieving improvement in defecation dynamics in a significant proportion of the biofeedback trained children. Regrettably, this improvement was not linked to functional improvement in continence. A similar result was recorded by van der Plas. ${ }^{12}$ This 
suggests that while anismus may be an important correlate of incontinence, it is not the principal or basic underlying aetiological mechanism. The treatment protocol evaluated in our study was designed to be consistent with practical and economic constraints, and with child and parent acceptability. A maximum of four sessions of biofeedback administered by the stomal therapist met these criteria and was adequate to achieve consistent external anal sphincter relaxation in all but one child. The possibility that further sessions could have improved the study outcome cannot be dismissed, but maintaining compliance once external anal sphincter relaxation had been achieved would have been difficult.

We found significant improvement in CBCL performance on the scholastic subscale in both the biofeedback and control groups, but the improvement in the biofeedback trained children was significantly greater. Unfortunately, we did not record where soiling episodes occurred, and cannot rule out the possibility that in the biofeedback group, although soiling was not reduced overall, soiling at school was decreased at the expense of soiling at home. This finding could reflect a beneficial effect of study monitoring and involvement in a comprehensive programme, which might have resulted in improved adherence to school routines, more positive responses from teachers, and improvements in children's perceived competence resulting from close clinical support and encouragement giving rise in turn to greater confidence with scholastic tasks. The beneficial effects of encopresis treatment on behavioural outcomes have been reported previously, ${ }^{217} 13$ and attributed to improvement in continence and the subsequent positive impact on the child's life in general. Therefore, the lack of improvement in CBCL behaviour scores in our study is consistent with the failure of treatment to improve continence.

The apparently encouraging results from uncontrolled studies, ${ }^{81011}$ and studies with limited follow up, ${ }^{15}$ have until now been used as justification for biofeedback training in children. However, biofeedback training is invasive, expensive, and labour intensive. ${ }^{18}$ The findings of our study, together with those recorded in the three other randomised controlled trials, now firmly argue against using biofeedback training in children with encopresis. ${ }^{19}$

The authors thank Diane Simpson for assistance with manometry, Associate Professor John Carlin for the randomisation, and the staff of the Royal Children's Hospital Biomedical Engineering Department for help with the biofeedback equipment. This ing Department for help with the biofeedback equipment. This
study was funded by grants from the National Health and Medical Research Council (grant 910621) and the Royal Children's Hospital Research Foundation.

1 Bellman M. Studies on encopresis. Acta Pediatr 1966;170(suppl): $1-154$.

2 Nolan TM, Debelle G, Oberklaid F, Coffey C. Randomised trial of laxatives in the treatment of childhood encopresis. Lancet 1991;338:523-7.

3 Nolan TM, Oberklaid F. New concepts in the management of encopresis. Paediatrics in Review 1993;14:447-51.

4 Loening-Baucke V. Biofeedback treatment for chronic constipation and encopresis in childhood: long-term outcome. Pediatrics 1995;96:105-10.

5 Johnston BD, Wright JA. Attentional dysfunction in children with encopresis. 7 Dev Behav Pediatr 1993;14:381-

6 Catto-Smith A, Nolan TM, Coffey C. The clinical significance of anismus in children with encopresis. $\mathcal{F}$ Gastroenterol Hepatol. [In press.]

7 Loening-Baucke V, Cruikshank B, Savage C. Defaecation Loening-Baucke $\mathrm{V}$, Cruikshank B, Savage C. Defaecation
dynamics and behaviour profiles in encopretic children. Pediatrics 1987;80:672-9.

8 Louis D, Valancogne G, Loras $\mathrm{O}$, Meunier P. Techniques et ndications du bio-feedback dans les constipations chez l'enfant. Psychol Med 1985;17:1625-7.

9 Wald A, Chandra R, Gabel S, Chiponis D. Evaluation of biofeedback in childhood encopresis. $\mathcal{F}$ Pediatr Gastroenterol Nutr 1987;6:554-8.

10 Keren S, Wagner Y, Heldenberg D, Golan M. Studies of manometric abnormalities of the rectoanal region during defaecation in constipated and soiling children. Am $\mathcal{F}$ Gastroenterol 1988;83:827-31.

11 Loening-Baucke V. Persistence of chronic constipation in children after biofeedback treatment. Dig Dis Sci 1991;36: $153-60$.

12 van der Plas RN, Benninga MA, Buller HA, et al. Biofeedback training in treatment of childhood constipation: a randomised controlled study. Lancet 1996; 348:776-8

13 van der Plas RN, Benninga MA, Redekop JA, Taminiau JA, Buller HA. Randomised trial of biofeedback training for encopresis. Arch Dis Child 1996;75:367-74.

14 Barr RG, Levine MD, Wilkinson RH, Mulvihall D. Chronic and occult stool retention. A clinical tool for its evaluation in school-aged children. Clin Pediatr 1979;18:674-86.

15 Loening-Baucke V. Modulation of abnormal defaecation dynamics by biofeedback treatment in chronically constipated children with encopresis. F Pediatr 1990;116:214-22.

16 Achenbach TM, Edelbrock, E. Manual for the child behaviour profile. Burlington, Vermont: University of Vermont, 1983.

17 Nolan TM, Coffey C, Oberklaid F, Bond L. Beneficial behavioural effects of successful encopresis therapy [abstract]. Am f Dis Child 1992;146:484.

18 Beach RC. Management of childhood constipation. Lancet 1996;348:766-7.

19 Loening-Baucke V. Biofeedback training in children with functional constipation: a critical review. Dig Dis Sci 1996; 41:65-71. 